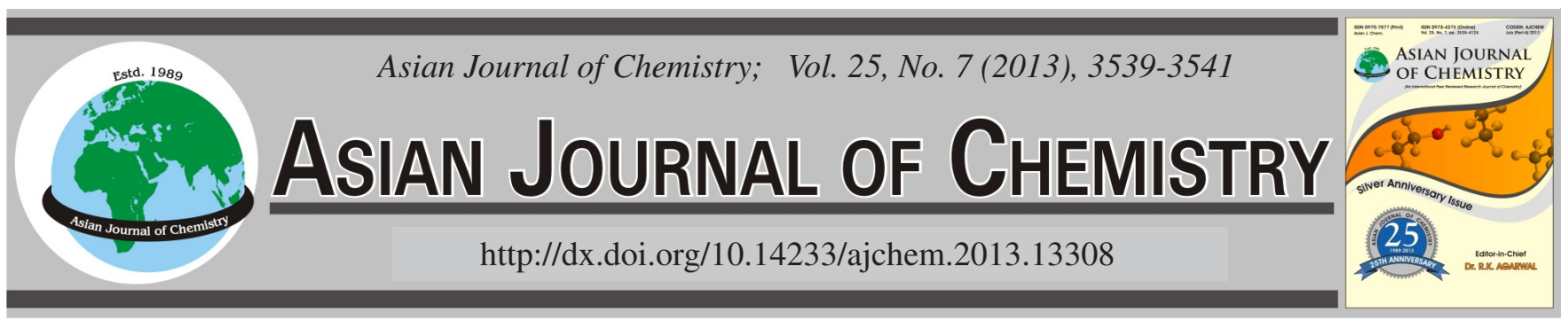

\title{
Effect of Temperature and Naproxen Sodium Over the Micellization Behaviour of N-Cetyl N,N,N-trimethyl ammonium bromide
}

Gulrez Fatima Durrani ${ }^{*}$, Musa Kaleem Baloch, Noor Saeed Khattak, Ayesha Niazi, Mohd. Irfan Ullah and Abdur Rauf

Department of Chemistry, Gomal University, Dera Ismail Khan, Pakistan

*Corresponding author: Tel: +92 3219605801; E-mail: drgulrez@yahoo.com

\begin{abstract}
Critical micelle concentration of $\mathrm{N}$-cetyl N,N,N-trimethyl ammonium bromide (CTAB) and its mixture with drug naproxen sodium were determined at different temperature by using surface tension technique. Naproxen sodium, a non-steroidal anti-inflammatory drug, which has been found to exhibit typical amphiphilic behaviour in aqueous solution in that they accumulate at interface, depressing the surface tension and form aggregate in solution at sufficiently high concentration. So critical micelle concentration of N-cetyl N,N,N-trimethyl ammonium bromide decreased as the concentration of drug increases and same is the case with temperature. Thermodynamic parameters like $\Delta \mathrm{G}_{\text {mic }}, \Delta \mathrm{H}_{\text {mic }}$ and $\Delta \mathrm{S}_{\text {mic }}$ of micellization of $\mathrm{N}$-cetyl N,N,N-trimethyl ammonium bromide were also determined in the presence of naproxen sodium salt at different temperature, which shows that free energy of micellization, is favoured in the presence of drug and become more favourable with the temperature.
\end{abstract}

Key Words: Surfactant, CTAB, Naproxen sodium, Effect of temperature, Cricital micelle concentration determination.

\section{INTRODUCTION}

Due to widespread uses of surfactants and industrial applications, the surfactants are used in almost every chemical industry ${ }^{1-3}$ e.g., detergents, paints, cosmetics, pharmaceutical, fibers and plastics. Water-soluble surfactants are used together in many formulations and industrial processes to determine the properties of the surfactant by the addition of polymer-14. Moreover, surface active agents play vital role in the oil industry. They are also used for environmental protection $e . g$., in oil slick dispersants a fundamental understanding of physical chemistry of surfactants is vital for the preparation of emulsion and suspension in foams. In micro emulsion, in wetting and adhesion, etc., the amphiphiles are of great importance in arriving at the right composition and control of the system involved.

Naproxen sodium is a widely used non-steroidal antiinflammatory drug which inhibits prostaglandin biosynthesis, or more specifically the enzyme cyclooxygenase ${ }^{1-3}$. The compound is a sodium salt of naproxen, its absorption is claimed to be more rapid compared to its parent naproxen. In the present paper, we reported the micellization at fixed temperatures and the clouding behavior of cetyl trimethylammonium bromide (CTAB) in the absence and presence of Naproxen sodium. The critical micelle concentration $(\mathrm{cmc})$ of CTAB was measured by surface tension technique.

\section{EXPERIMENTAL}

The surfactant used during this work was cetyl trimethyl ammoniumbromide (CTAB), m.w. = $364.44 \mathrm{~g} / \mathrm{mole}$ having molecular formula $\mathrm{C}_{19} \mathrm{H}_{42} \mathrm{NBr}$ obtained from Merck Germany. Naproxen sodium (drug) having molecular formula $\mathrm{C}_{14} \mathrm{H}_{13} \mathrm{O}_{3} \mathrm{Na}$, m.w. $=252.24 \mathrm{~g} / \mathrm{mol}$, which was kindly supplied by Chong Kun Dang Co. Ltd.

Conductivity water was used as a solvent, whose conductance ranged from $5-7 \mu \mathrm{S} / \mathrm{cm}$.

Sample preparation: Known concentration of CTAB was prepared in deionized water as a stock solution. Solutions of different concentration were obtained by diluting stock solution. The solution of $0.001 \mathrm{M}$ naproxen sodium was also prepared.

Surface tension measurement: TE3 LAUDA tensiometer, supplied by LAUDA, Germany was used to measure the surface tension of the prepared solutions. All measurements were made sufficiently slowly so as to ensure equilibrium conditions. The measurements were made for different concentrations and at different temperatures i.e., 20, 30 and $40{ }^{\circ} \mathrm{C}$. The temperature was maintained using Ecoline Circulation Thermostat Model E 015T, Germany, which retained the temperature to $\pm 0.01{ }^{\circ} \mathrm{C}$.

\section{RESULTS AND DISCUSSION}

The results obtained from the surface tension measurement of surfactant CTAB in an aqueous media in the temperature 
range of $20-40^{\circ} \mathrm{C}$ are plotted in Fig. 1. It is clear from the data obtained that at first the surface tension decreases slowly till it reaches to a point which is known as critical concentration of the surfactant (CC), further increase in concentration decreases the surface tension sharply and ultimately leads to a minimum value of surface tension which shows the adsorption of surfactant at the air-water interface and then becomes constant. This point at which surface tension become level off is known as critical micelle concentration $(\mathrm{CMC})^{15,16}$. Further increase in concentration of the surfactant does not alter the surface tension; however, it can increase size and change the shape of micelles ${ }^{17}$. It is clear from the plot of surface tension $v s$. log of concentration of CTAB (Fig. 1) that the surface tension of CTAB also decreases as the temperature increases, which is due to changes in the solvent-solute interactions and results in decrease in surface tension of $\mathrm{CTAB}^{18}$.

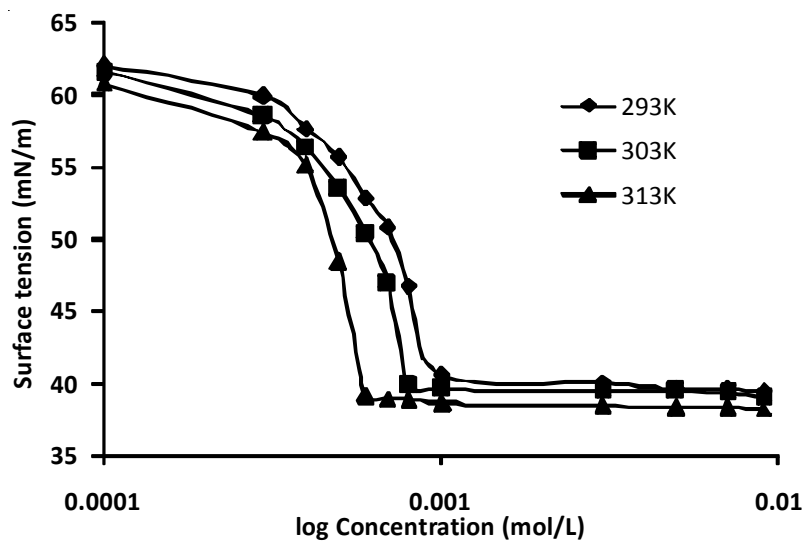

Fig. 1. Surface tension of CTAB as a function of its concentration

Surface tension of CTAB and its mixture with naproxen sodium were plotted as a function of $\log$ of concentration of CTAB and plotted in Fig. 2. Fig. 2 shows the decreasing trend of surface tension with the increasing concentration, which is same as that of CTAB in aqueous solution i.e., first surface tension decreases slowly, then in the second step surface tension decreases sharply with the increase in concentration and then levels off in the third step. The CMC value is calculated from the point where two straight lines intersect. The CMC values calculated from the intersection of two straight lines are presented in Fig. 3 (Table-1) which shows that the critical micelle concentration of CTAB decreases with increase in temperature. This decrease in the CMC of CTAB with temperature increase is possibly due to more hydrophobicity and dehydration of the monomers in the solution. However the effect of temperature on CMC is complex, firstly temperature increase cause decreased hydration of the hydrophilic group, which favours micellization. Secondly, temperature increase also causes disruption of the structured water around the hydrophobic groups which opposes micellization ${ }^{16,19}$. Here, the effect of temperature on the $\mathrm{CMC}$ is more pronounced.

The results obtained from the plot of CMC of CTABnaproxen sodium against volume of $0.001 \mathrm{M}$ naproxen sodium added (Fig. 4) at a constant temperature shows that with increase in volume of naproxen sodium, $\mathrm{CMC}$ decreases which means that it favours micellization. The reason is that the molecules solubilized in the outer portion of the micelle core

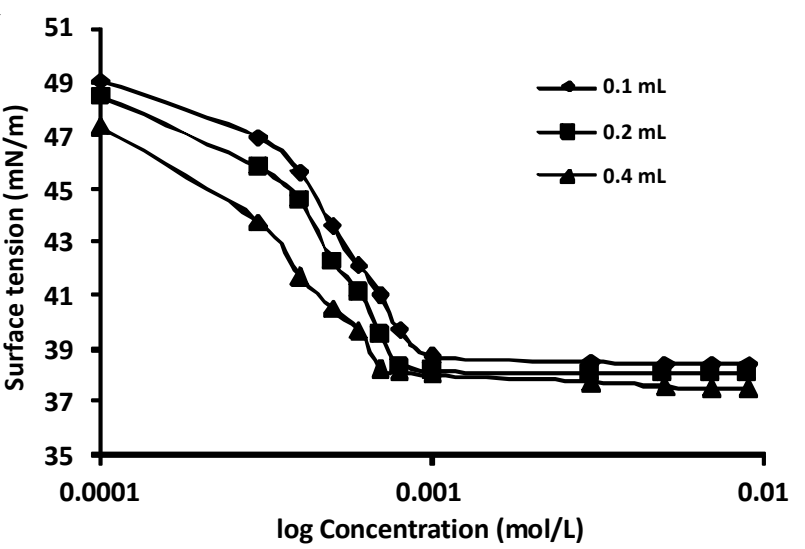

Fig. 2. Surface-active behavior of CTAB in the presence of naproxen sodium

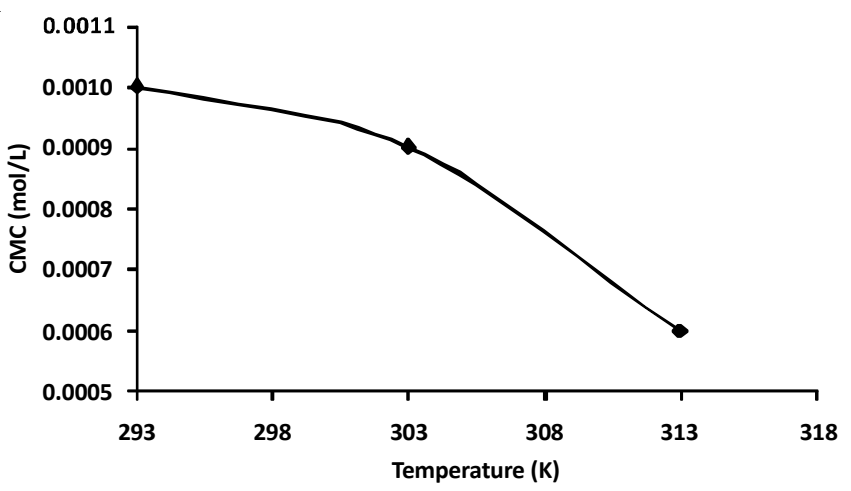

Fig. 3. CMC of CTAB as a function of temperature

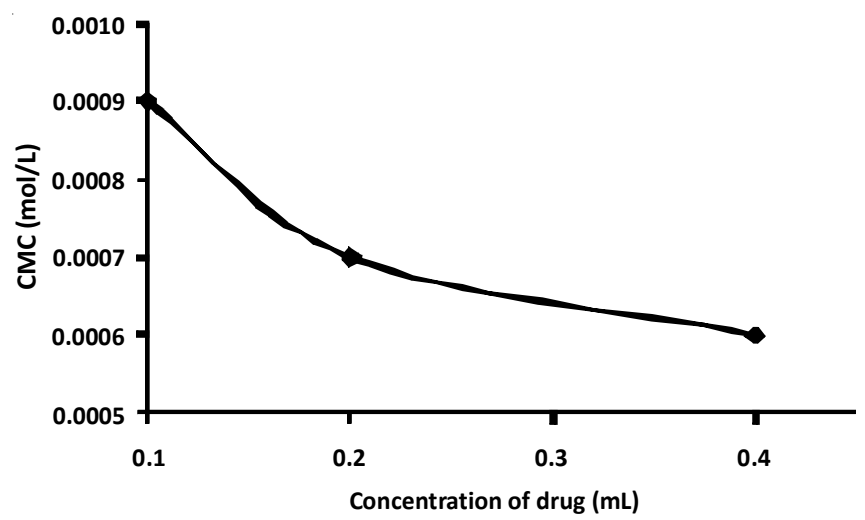

Fig. 4. CMC of CTAB-drug mixture plotted against volume of drug added

which is effective in reducing the CMC. The electrostatic interactions between $\mathrm{CTAB}$ and naproxen sodium decreases the repulsive forces between the head groups of surfactant molecules which favour micellization process, therefore, cause decrease in the CMC values (Table-1). As a result of decrease in the CMC, the solubility of naproxen sodium is enhanced in the micellar solution due to electrostatic forces of interactions $\mathrm{s}^{20}$.

Thermodynamics of micellization: Different thermodynamic parameters of micellization of CTAB and its mixture with drug calculated are plotted in Figs. 3-6 (Tables 1 and 2). Change in free energy of micellization calculated from the most common thermodynamic equation:

$$
\Delta \mathrm{G}_{\text {mic }}^{\mathrm{o}}=\mathrm{RT} \ln \mathrm{CMC}
$$

$\Delta \mathrm{G}^{\mathrm{o}}$ mic is negative which shows that micellization process is spontaneous and the negative value increases with increase in temperature which shows that the micellization process 


\begin{tabular}{cccccc}
\hline \multicolumn{6}{c}{ TABLE-1 } \\
\multicolumn{7}{c}{ THERMODYNAMIC PARAMETERS OF MICELLIZATION OF } \\
CTAB AT DIFFERENT TEMPERATURE \\
\hline $\begin{array}{c}\text { Temp. } \\
(\mathrm{K})\end{array}$ & $\begin{array}{c}\mathrm{CMC} \\
\left(\mathrm{mol} \mathrm{L}^{-1}\right)\end{array}$ & $\begin{array}{c}\gamma_{\mathrm{cmc}}(\mathrm{mN} \\
\left.\mathrm{m}^{-1}\right)\end{array}$ & $\begin{array}{c}\Delta \mathrm{G}_{\text {mic }}(\mathrm{KJ} \\
\left.\mathrm{mol}^{-1}\right)\end{array}$ & $\begin{array}{c}\Delta \mathrm{S}_{\text {mic }}(\mathrm{KJ} \\
\left.\mathrm{mol}^{-1} \mathrm{~K}^{-1}\right)\end{array}$ & $\begin{array}{c}\Delta \mathrm{H}_{\text {mic }}(\mathrm{KJ} \\
\left.\mathrm{mol}^{-1}\right)\end{array}$ \\
\hline 293 & 0.001 & 40.67 & -26.61 & 0.242 & 44.296 \\
303 & 0.0009 & 39.86 & -27.785 & 0.243 & 45.819 \\
313 & 0.0006 & 39.09 & -29.757 & 0.246 & 47.241 \\
\hline
\end{tabular}

\begin{tabular}{cccc} 
TABLE-2 \\
$\begin{array}{c}\text { THERMODYNAMIC PARAMETERS OF MICELLIZATION OF } \\
\text { CTAB-NAPROXEN SODIUM MIXTURE }\end{array}$ \\
\hline $\begin{array}{c}\text { Volume of } 0.001 \mathrm{M} \\
\text { drug added }(\mathrm{mL})\end{array}$ & $\begin{array}{c}\mathrm{CMC} \\
\left(\mathrm{mol} \mathrm{L}^{-1}\right)\end{array}$ & $\begin{array}{c}\gamma_{\text {cmc }} \\
\left(\mathrm{mN} \mathrm{m}^{-1}\right)\end{array}$ & $\begin{array}{c}\Delta \mathrm{G}_{\text {mic }} \\
\left(\mathrm{KJ} \mathrm{mol}^{-1}\right)\end{array}$ \\
\hline 0.1 & 0.0009 & 38.69 & -26.868 \\
0.2 & 0.0007 & 38.42 & -27.480 \\
0.4 & 0.0006 & 38.26 & -27.855 \\
\hline
\end{tabular}

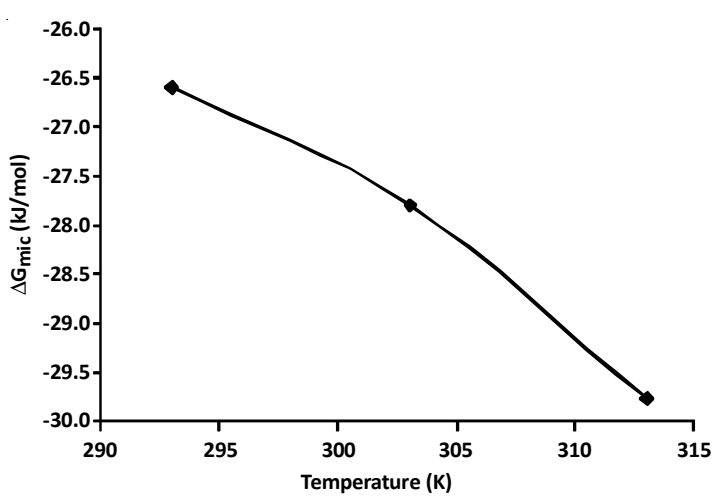

Fig. 5. $\Delta \mathrm{G}_{\text {mic }}$ of CTAB in aqueous plotted vs. temperature

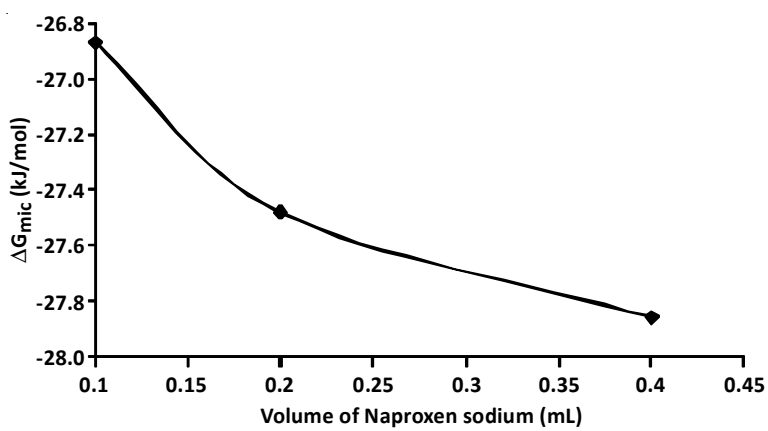

Fig. 6. $\Delta \mathrm{G}_{\text {mic }}$ of CTAB-naproxen sodium vs. volume of drug added

becomes more spontaneous with increase in temperature ${ }^{21}$. Change in the free energy of micellization $\Delta \mathrm{G}^{\circ}$ mic of CTABnaproxen sodium mixture calculated from eqn. 1 is illustrated in Fig. 6 (Table-2). The $\Delta \mathrm{G}_{\text {mic }}^{\mathrm{r}}$ values for each volume of naproxen sodium added in CTAB solution are negative which shows that micellization process is spontaneous and it become more negative as the concentration of drug increase indicating the more spontaneous nature of micellization process in the presence of naproxen sodium, which shows that solubilization process is more favourable in this system due to decrease in the $\mathrm{CMC}$ and increased negative value of free energy ${ }^{27}$. The enthalpy of micellization was calculated by using the GibbsHelmholtz equation:

$$
\Delta \mathrm{H}_{\text {mic }}^{\mathrm{o}}=\left[\frac{\frac{\partial\left(\Delta \mathrm{G}^{\mathrm{o}}{ }_{\text {mic }}\right.}{\mathrm{T}}}{\partial\left(\frac{1}{\mathrm{~T}}\right)}\right]
$$

Putting the value of $\Delta \mathrm{G}_{\text {mic }}^{\mathrm{o}}$ from eqn. 1 we get:

$$
\Delta \mathrm{H}^{\mathbf{o}}{ }_{\text {mic }}=\mathrm{R}\left[\frac{\partial \ln \mathrm{CMC}}{\partial(1 / \mathrm{T})}\right]
$$

In the above equation, the term $\left[\frac{\partial \ln \mathrm{CMC}}{\partial(1 / \mathrm{T})}\right]$ was calculated from the slope of the tangent to a plot of ln CMC versus $1 / \mathrm{T}$. A slight increase in $\Delta \mathrm{H}^{\mathrm{o}}$ mic values, with changing the temperature was observed. $\Delta \mathrm{H}^{\mathrm{o}}$ mic is positive at all temperatures, which indicate the endothermic nature of micellization ${ }^{21-23}$.

After knowing the values of $\Delta \mathrm{G}^{\mathrm{o}}$ mic and $\Delta \mathrm{H}^{\mathrm{o}}$ mic the values of entropy of micellization $\Delta S_{\text {mic }}^{o}$ were calculated from the well known thermodynamic relation which is as follows:

$$
\Delta \mathrm{S}_{\text {mic }}^{\mathrm{o}}=\Delta \mathrm{H}^{\mathrm{o}}{ }_{\text {mic }}-\frac{\Delta \mathrm{G}^{\mathrm{o}}{ }_{\text {mic }}}{\mathrm{T}}
$$

The values so obtained are positive at all temperatures indicating greater disorder/randomness in the system upon micelle formation ${ }^{21}$.

\section{ACKNOWLEDGEMENTS}

Ayesha Niazi, Abdur Rauf and Mohdammad Irfan Ullah are highly thankful to Higher Education Commission(HEC), Pakistan for the financial support under indigenous Ph.D fellowship Scheme. Further, Noor Saeed Khattak also shows special thanks to Department of Chemistry and High Tech. Research Center, Gomal University, Dera Ismail Khan, Pakistan for providing the research facilities.

\section{REFERENCES}

1. M.-R. Porter, Hand Book of Surfactant Blackie, Glasgow (1991).

2. Th.-F. Tadros, Surfactants, Academic Press, London (1984).

3. D. Myers, Surfaces, Interfaces and Colloids, VCH, New York (1991).

4. B. Mohamed, B. Barney and R. Zana, J. Colloid Interf Sci., 267, 519 (2003).

5. E.-D. Goddard and K.-P. Ananthapadmanabhan, Interactions of Surfactants with Polymers and Proteins; CRC Press: Boca Raton, Florida (1993).

6. D. Langevin, Adv. Colloid Interf. Sci., 467, 89 (2002).

7. J. Funjin and W. Brown, Macromolecules, 27, 5024 (1994).

8. G.-F. Durrani, M.K. Baloch and G. Hameed, J. Chem. Soc. Pak., 3, 26 (2004).

9. J. Taber, J. Pure Appl. Chem., 52, 1323 (1980).

10. P. Bahadur and G. Reiss, Tenside Surf. Deterg., 28, 173 (1991).

11. P.-N. Hurter and T.-A. Hatton, Langmuir, 8, 1291 (1992).

12. P. Alexandridis, Curr. Opin. Colloid Interf. Sci., 1, 490 (1996).

13. K. Suzuki, Y. Saito, Y. Tokuoka, M. Abe and T. Sato, J. Am. Oil. Chem. Soc., 74, 55 (1997).

14. M.-K. Baloch, G. Hameed and A. Bano, J. Chem. Soc. Pak., 24, 77 (2002).

15. M.-R. Porter, Hand Book of Surfactant, pp. 129-33 (1999).

16. G.S. Hartley, Aqueous Solution of Paraffin Chain Salts, A Study in Micelle Formation, Hermann et Cie, Paris (1936).

17. D. Attwood and A.-T. Florence, Surfactant Systems, Chapman and Hall Ltd, London (1983).

18. A. Khan, G. Fatima, M. Usman, W. Harrison and M. Siddiq, J. Chem. Soc. Pak., 31, 534 (2009).

19. M.-K. Baloch, A. Farzana, A. Rauf and G. Fatima, J. Appl. Polym. Sci., 114, 1444 (2009).

20. C.-O. Rangel-Yagui, H.-W.-L. Hsu, A. Pessoa-Jr. and L.-C. Tavares, J. Pharm. Pharm. Sci., 41, 237 (2005).

21. M.-J. Rosen, Surfactants and Interfacial Phenomena. Wiley-Interscience Publication (1978).

22. P.C. Heimenz and R. Rajagopalan, Principles of Colloid and Surface Chemistry, edn. 3.

23. C.-O. Rangel-Yagui, H.-W.-L. Hsu, A. Pessoa-Jr. and L.-C. Tavares, J. Pharm. Pharma. Sci., 41, 237 (2005). 